\author{
Aleksandra Lopińska
}

\title{
Материальное положение, класс, раса. Частная собственность как фактор, регулирующий современные социальные дифференциации
}

В самом широком смысле этого слова частная собственность может определяться как все то, что находится в личном владении собственника - непубличного лица. Согласно формулировке, содержащейся в польском законодательстве,

\begin{abstract}
в рамках, определенных законами и принципами общественного сосуществования, владелец может, за исключением иных лиц, пользоваться вещью в соответствии с социально-экономическим предназначением своего права, в особенности получать пользу и иные доходы от использования вещи. В тех же самых рамках он может вещью распоряжаться [ст. 140 Ustawy Kodeks Cywilny (Польский Гражданский Кодекс)]
\end{abstract}

В этой формулировке указаны две области, для которых идея частной собственности (независимо от того, принимается ли она или отвергается) имеет ключевое значение: общественный порядок и экономика.

Исходным положением данной работы является стремление отмежеваться от экономических следствий полного или частичного принятия или отвержения концепции частной собственности, в пользу более глубокого анализа влияния, какое оказывает она на современные взаимоотношения в обществе. Иначе говоря, - каким образом складываются естественные и неестественные отношения между группами, выделяемыми на основании дифференцированного экономического статуса их членов. Разделение на более богатых и более бедных, осуществляемое на основании субъективной оценки наличествующего имущества отдельных личностей, является очевидным и принимаемым показателем дифференциаций внутри любого человеческого коллектива. Однако ситуация, в которой общественная мобильность нарушена, а проведенные таким об-

1 Dz. U. 1964. № 16, Ст. 93. 
402 | Adam Mickiewicz University Law Review

разом границы становятся непроницаемыми или таковыми считаются, находится уже в категории нежелательных явлений, или даже - в крайних случаях - патологических. Речь идет о том моменте, в котором в общественных позициях и действии можно усмотреть явную линию, связывающую восприятие частной собственности (и особенно ее распределение) с созданием классовых и расовых дифференциаций.

\title{
1. Проблема оценки частной собственности
}

Полемика на тему института частной собственности продолжается как минимум со времен античности. И если Платон считал ее источником страданий, являющихся следствием несправедливого раздела благ, то его ученик и критик - Аристотель - обращал внимание на бесспорно положительные свойства собственности, усматривая в ней, кроме всего прочего, источник различный добродетелей, в том числе рассудительности и ответственности ${ }^{2}$. Дискуссия по этому вопросу развивалась с течением времени, привлекая к себе внимание публицистов и философов и сегодня. Джон Локк в своих рассуждениях, касающихся этики и политики, затрагивает вопрос о трех основных правах человека, к которым он относит - наряду с правом на жизнь и свободу - также право на собственность (в значении частной собственности) ${ }^{3}$. С другой стороны, хотя сегодня охотнее всего и цитируют трактат Об общественном договоре ЖанЖака Руссо с 1762 г., в котором автор представляет эскиз своего проекта общества, основанного на свободе и уважении права собственности, стоит отметить, что именно он, семью годами ранее, писал:

\begin{abstract}
Первый, кто огородил клочок земли, осмелился сказать: эта земля принадлежит мне, и нашёл людей, которые были настолько простодушны, чтобы поверить этому, был истинным основателем гражданского общества. Сколько преступлений, сколько войн, сколько бедствий и ужасов отвратил бы от человеческого рода тот, кто, вырвав столбы или, засыпав рвы, служившие границами, воскликнул бы, обращаясь к людям: [Берегитесь слушать этого обманщика! Вы погибли, если забудете, что плод принадлежит всем, а земля -никому!] (... $)^{4}$.
\end{abstract}

В истории новейшего времени произошло идеологическое и политическое столкновение двух систем: одна из них была основана на частной собственности, а вторая ста-

\footnotetext{
2 J. Waldron, Property and Ownership, Stanford Encyclopedia of Philosophy.

3 Позднее Иммануил Кант, формулируя проект частного права, признает собственность фундаментальным институтом. См. О. Höffe, Mała historia filozofii, Warszawa 2004, С. 140 и 168.

4 O. Höffe, Mała historia ..., C. 151.
} 
ралась ее исключить. Идейным вдохновителем этой последней был, главным образом, Карл Маркс, утверждавший, что частная собственность сделала нас столь глупыми и односторонними, что какой-нибудь предмет является нашим лишь тогда, когда мы им обладаем ${ }^{5}$, а коммунизм есть положительное выражение упразднения частной собственности ${ }^{6}$. В свою очередь сторонники и популяризаторы либеральной, а позднее неолиберальной мысли, на которой основана современная капиталистическая система, неизменно провозглашают противоположное. Здесь можно упомянуть хотя бы Людвига фон Мизеса, который утверждал, что

если история могла бы нас хоть чему-нибудь научить, то несомненно тому, что ни один народ не создал высшей цивилизации без уважения права на владение частной собственностью7.

Парадоксом этого многовекового спора является факт, что практически все, что в нем участвовал, отчасти были правы. Радикальные различия в позициях являются результатом принятия отдельными мыслителями отличных друг от друга исходных пунктов для дальнейших рассуждений. Это очевидно, что мы придем к диаметрально противоположным эффектам, рассматривая проблему частной собственности в контексте социальной справедливости и эффективности управления (при этом стоит подчеркнуть, что оба этих термина сами по себе спорны и неоднозначно определены). Сложность вопроса склоняет нас к тому, чтобы отойти от оценки как самой собственности, так и концепции ее полного принятия или же частичного или полного отрицания. Здесь просто-напросто нет однозначно хороших или плохих решений, а сам факт, что определенный общественный порядок или экономическая система подвергаются сомнению представителями некоторых интеллектуальных кругов, не означает автоматически, что он неверен. И хотя крайне трудно, если не невозможно, полностью отделить какие-либо современные размышления относительно роли собственности от трудов мыслителей, занимавшихся этим вопросом не одну тысячу лет, в данной работе мы будем избегать определения каких-либо концепций или течений в истории экономической или философской мысли главенствующими. Дело не в том, чтобы представить проблему социальных дифференциаций с перспективы марксистской или неолиберальной мысли, а в том, чтобы указать некоторые - часто шокирующие - спо-

5 K. Marks, Kapitał, Warszawa 1951, C. 581.

6 K. Marks, Kapitat, C. 575.

$7 \mathrm{~W}$. Walicki, Jeśli historia mogłaby nas czegokolwiek nauczyć, to niewątpliwie tego, że żaden naród nie stworzył wyższej cywilizacji bez poszanowania prawa do posiadania własności prywatnej [online]. Instytut Misesa [Доступ: 2013-06-21]. Доступны на: http://mises.pl/ blog/perfect-quotes/jesli-historia-moglaby-nas-czegokolwiek-nauczyc-to-niewatpliwie-tegoze-zaden-narod-nie-stworzyl-wyzszej-cywilizacji-bez-poszanowania-prawa-do-posiadaniawlasnosci-prywatnej>. 
404 | Adam Mickiewicz University Law Review

собы восприятия качества определенных групп людей сквозь призму накопленной ими частной собственности.

Надежными можно в этой ситуации исходно признать не оценочные суждения, а факты. Трудно полемизировать с утверждением, что исторически превалировали и были более предпочтительными такие способы общественной организации, которые все же признавали институт частной собственности - мы обнаружим ее и в традиционных экономиках, при феодализме, в различных вариантах свободного рынка и, наконец, также в качестве дополнения (даже если неофициально и маргинально, как это имело место в СССР) плановой экономики. С точки зрения эффективности управления крупными общественными группами признание частной собственности приносило в долгосрочной перспективе гораздо лучшие результаты, чем ее отрицание. Также фактом, весьма очевидным и имеющим долгую историческую традицию, является формирование межгрупповых дифференциаций именно на основании имущественного критерия, а также введение на той же основе категоризации на теx, что лучше и тех, что хуже, о чем мы будем говорить ниже.

\section{2. Частная собственность, класс, раса}

Признание частной собственности обусловливает выделение более богатых и более бедных групп, что является логическим следствием ограниченных ресурсов в экономике (как мировой, так и национальной). Другим, с социологической точки зрения более важным последствием приватизации материальных благ становится распространение в общественном мнении убежденности в личностной ответственности за собственный материальный статус. Иными словами, в ситуации, когда это не коллектив и не государство, а личность в большей степени отвечает за накопление и управление собственностью, то исключительно на ней лежит обязанность обеспечить для себя соответствующий уровень жизни, и только она должна нести ответственность за последствия упущений в этом вопросе. Это упрощенное убеждение приносит некоторое искажение действительности - все же не всегда количество собранной в частных руках собственности является функцией интеллектуальной предрасположенности, образования или работоспособности владельца. Это порождает двойственный антагонизм: среди самых бедных часто появляются голоса, что богатые разбогатели нечестным путем (почему они имеют больше, если они не работают больше нас), и наоборот, люди состоятельные нередко относятся к более бедным как к неспособным или слишком ленивым, чтобы обеспечить себе экономический успех (если бы умели и хотели, могли бы иметь больше).

Подобные межгрупповые антагонизмы, хотя и проблематичны, редко становятся внезапными и трудно их назвать социальной патологией. Эта последняя проявляется, 
тем не менее, в двух случаях: или когда восприятие материального статуса данной группы сопряжено с неприязнью в этническом (возможно, религиозном) плане, или когда принадлежность к более бедному социальному слою воспринимается как эквивалент расовой принадлежности.

Первая из упомянутых ситуаций имеет место, когда в коллективном сознании появляется убеждение о том, что способность данной группы - любой чужой по национальному, религиозному или этническому признаку - накапливать частную собственность является степенью угрозы, которую она создает (фактически или потенциально). В этом случае как состоятельность, так и бедность, могут быть обличаемы, что очень хорошо иллюстрирует отношение к евреям в Европе нового времени. Исторически эта группа воспринималась как естественным образом более бедная по очевидным соображениям - ее представителям нельзя было владеть землей, которая столетиями являлась основой создания социального и имущественного статуса. Среди небольшого количества доступных источников заработка евреи зачастую выбирали денежный оборот, что и так не гарантировало им особенно высокий доход. Если они относились к более бедной социальной группе (а так было в большинстве случаев), им приписывалась бо́льшая склонность к совершению преступлений, бо́льшая подверженность различным болезням и т.д. Зарождение капитализма не только полностью лишило актуальности тенденцию обличения денежного оборота как несоответствующего христианским принципам ростовщичества, но и совсем наоборот - сделало из него нужную и привлекательную профессию. Таким образом, изменение хода истории отразилось на имущественном статусе некоторой часть еврейской диаспоры. Как следствие появились известные нам в настоящее время теории о мировом еврейском заговоре, в соответствии с которым евреи, используя свои сильные экономические позиции, реализуют собственные интересы посредством оказания влияния на правительства отдельных государств. Разумеется, предшествующие предубеждения остались в силе - прибывающие в Западную Европу в начале XX в. еврейские эмигранты воспринимались как бедный (а, следовательно, криминогенный) и живущий в ужасающих условиях (а посему создающий эпидемиологическую угрозу) сброд. Кратко подытоживая этот многовековой дискурс ненависти: если еврей бедный, это очень плохо, а если богатый - еще хуже. На такой подход к этой конкретной группе влияли, разумеется, факторы, главным образом, внеэкономические. Тем не менее, материальный статус ее членов был всегда существенным элементом создания сначала ксенофобских, а позднее расистских теорий. В этом месте следует добавить, что подобным образом фактор этнических или религиозных предубеждений сплетается в настоящее время с неприязнью по отношению к чужим, в том числе, прежде всего, к эмигрантам, возрастающей на фоне их материального положения. С одной стороны исключаются из нормального

8 Z. Bauman, Modernity and the Holocaust, Нью-Йорк 2000, С. 225. 
406 | Adam Mickiewicz University Law Review

участия в общественной жизни прибывшие наёмные рабочие, которые - что является закономерностью практически во всем мире - располагают меньшей экономической силой, чем группы, их принимающие, а с другой - клеймятся немногочисленные, но состоятельные заграничные инвесторы, особенно, если они относятся к иному культурному или религиозному кругу 9

В случае, когда имущественный критерий, т.е. собранная в частных руках собственность, является основой, а не только дополнительным фактором по отношению к иным свойствам, служащим определению качества людей, возникающие социальные дифференциации и их последствия не менее сложны. Речь идет о ситуации, когда значение этнического происхождения, конфессии или физических черт людей снижается, и происходит группировка и приклеивание ярлыков более высокой или более низкой ценности личности на основании ее врожденной, неотъемлемой неспособности к накоплению состояния. Каким образом это соотносится с проблемой расизма или связанной с ним евгеники?

Расизм в соответствии со своим самым широким определением связан с сегрегацией людей на высшие и низшие группы по соображениям совокупности их врожденных, неотъемлемых физических и умственных черт. Это общее объяснение следует дополнить двумя оговорками. Во-первых, расизм - это продукт современности ${ }^{10}$. Его существование в нынешней форме было бы невозможно, среди прочих равных, без интеллектуальной революции эпохи Просвещения, когда в науке стало популярным стремление классифицировать практически все, в том числе живых существ, исходя из соображений их генеалогии и наблюдаемых свойств ${ }^{11}$. Предыдущие, исторические социальные антагонизмы, взращённые на фоне инаковости отдельных групп, были связаны скорее с различиями в исповедуемой ими религии или их происхождении с различиями, которые неотъемлемыми не были, поскольку неверный всегда мог обратиться, а варвар - получить гражданство, что часто решало проблему чужеродности ${ }^{12}$. А посему можно было говорить о ксенофобии, не о расизме. Во-вторых, в XIX и XX вв. культурная и религиозная принадлежность, а также экономический статус воспринимались как эквивалент расы, независимо от того, какими физическими чертами характеризовались личности, считавшиеся членами pac, выделенных в соответствии с этими современныли, расширенными критериями. Одновременно, в связи с развитием национализмов и ростом популярности идеи социальной инженерии, появляется стремление к плановому производству оптимального общества, лишенного дефектов

9 E. Balibar, Class Racism, в: I. Wallerstein, E. Balibar, ред., Race, Nation, Class. Ambiguous identities, Лондон - Нью-Йорк 1991, С. 206.

10 Z. Bauman, Modernity..., C. 212-213.

11 C. West, A Genealogy of Modern Racism, в: P. Essed, D.T. Goldberg, ред., Race Critical Theories: Text and Context, Оксфорд 2002, C. 90-112.

12 G.M. Frederickson, Racism. A short history, Принстон-Оксфорд 2002, C. 17-47. 
и неприспособленных личностей ${ }^{13}$. Сплетение этих всех обстоятельств привело в новейшей истории к расцвету межчеловеческих дифференциаций, нарастанию различных форм расизма, и в конце концов к развитию евгеники.

По отношению к личностям, считающимся более плохими в расовом отношении, применяются две стратегии: или включение их в общество в качестве группы безусловно второсортной, либо абсолютное их исключение, а в крайних случаях - физическое истребление ${ }^{14}$. Ниже нам хотелось бы обсудить два случая, связанные в том числе с дифференциациями на экономическом фоне, в которых эти стратегии находят свое выражение: так называемый классовый расизм и применение евгеники в XX веке.

Рыночная экономика и капиталистическая система очевидным образом связаны с разделением на тех, кто имеет средства производства и сосредотачивает в своих руках капитал, и тех, кто функционирует как наёмная рабочая сила и располагает относительно небольшими ресурсами частной собственности. К этой второй группе относятся, наряду со средними классами, также самые бедные слои. И эти последние, в соответствии с тезисами, выдвинутыми И. Валлерстаном и Э. Балибаром, в настоящее время являются объектом клеймения расового характера, т.е. их общее материальное положение и социальная ситуация составляют субститут традиционно понимаемой pacbl. Как отмечает И. Валлерстайн, в капиталистической системе исключение коголибо лишено в экономическом плане смысла, потому что все, как актуальная или потенциальная рабочая сила, имеют с точки зрения экономики определенную ценность. В связи с этим, различные группы, независимо от своей этнической, национальной и религиозной принадлежности, всегда в системе:

\begin{abstract}
(...) и всегда занимают какое-то место в иерархии, хоть не всегда одно и тоже. Некоторые группы могут перемещаться между позициями в системе; некоторые могут исчезать или объединяться с другими, а еще некоторые распадаются и возникают новые. Но всегда [в системе] присутствуют такие, которые являются неграми. Если слишком мало чернокожего населения, можно ввести категорию бельх негров ${ }^{15}$.
\end{abstract}

Э. Балибар развивает мысль, касающуюся клеймения определенных имущественных классов еще более подробно. Он, среди прочего, отмечает, что сообщество, называемое им раса работников (в значении самых бедных), становится предметом расистского дискурса, который в настоящее время сочетает в себе целую гамму черт, приписываемых данной группе в связи с местом, занимаемым ей в экономической системе,

13 Z. Bauman, Modernity..., C. 19-42.

14 G.M. Frederickson, Racism..., C. 9-10.

15 I. Wallerstein, The Ideological Tensions of Capitalism: Universalism versus Racism and Sexism, в: I. Wallerstein, E. Balibar, ред., Race, Nation, C. 34. 
в том числе материальная и духовная бедность, преступное поведение, алкоголизм, наркомания, физические и моральные дефекты, низкий уровень гигиены и т.д ${ }^{16}$. В своих рассуждениях Балибар затрагивает также проблему расификации (анг. racialization) физического труда. Он ссылается на работу Ф. Тейлора Принщипы научного менеджмента (1909 г.), в которой автор представляет теорию о существовании людей, естественным образом предрасположенных к выполнению тяжелой, грязной и монотонной работы, а, кроме того, нуждающихся в ком-то, кто будет над ними стоять и управлять, чтобы они могли работать в соответствии со своей природой. Такой образ мышления о физическом работнике как о личности, второсортной с рождения, нашел свое выражение не только в отношении к людям, работавшим на фабриках во времена раннего капитализма, но и в наше время - в эпоху механизированного производства, когда человек выполняет монотонные и утомительные действия у станка ${ }^{17}$. Следует в этом месте добавить, что как И. Валлерстайн, так и Э. Балибар, в различной степени ссылаются на марксизм, многие свои теории практически на нем и основывая. Можно не соглашаться с Марксом и критиковать резкость выражения двух представленных выше автором. Не рекомендуется также интерпретация их концепций, касающихся социальных дифференциаций в качестве критики института частной собственности. Однако независимо от занимаемой ими позиции, трудно согласиться, что ситуации, в которых происходит, например, машинальная ассоциация бедности с патологией, или когда верх социальной имущественной лестницы с высока, а иногда и с презрением смотрит на низ, являются оторванными от современной действительности идеями теоретизирующих последователей Маркса.

И, наконец, последний вопрос, который нам хотелось бы затронуть, это широко распространившаяся в XX веке евгеника, являющаяся реализацией концепции социальной инженерии. Она вписывается в стратегию социального исключения личностей, заклейменных как качественно худиих. Термин евгеника (от гр. eugenes - хорошего рода) был введен в конце XIX в. Френсисом Гальтоном, который утверждал, что каждый человек является отражением черт его предков. Его идея положила начало развитию так называемой положительной евгеники, т.е. поощрение людей, характеризующихся лучшими чертами, к объединению в пары и размножению, и отрицательной евгеники (которая позднее выйдет на первый план), т.е. насильственное, физическое исключение из сообщества тех личностей, которые признаны носителями худшего генетического материала. Это все, разумеется, должно служить сознательному проектированию оптимального общества, свободного от дефектов и неприспособленных людей. Самым трагическим по своим последствиям применение евгеники имело место в Третьем Рейхе, однако это не нацисты первыми использовали ее атакующий вариант. Первой организацией, реализовавшей общественные вмешательства согласно 16 E. Balibar, Class..., C. 209.

17 E. Balibar, Class..., C. 210-211. 
идее отрицательного понимания евгеники, была American Breeders Association (ABA). В 1911 г., во время одной из встреч этого объединения, его главные члены определили десять групп социально неприспособленных и - в последствии - предназначенных к уничтожению людей. В нем оказались недоразвитые личности (хотя недоразвитие не было определено никаким явным образом), преступники (в этой категории оказались также люди, виновные в мелких нарушениях), эпилептики, сумасшедшие и др. Что самое интересное с перспективы данной работы - группа номер два явственно была определена как бедный класс (анг. pauper class) ${ }^{18}$. Ее члены, характеризующиеся неотъемлемой и обусловленной наследственно склонностью к нищете, неспособностью к накоплению собственности, были признаны не имеющими права на размножение. На практике, люди, которых можно было отнести к перечисленным выше категориям, становились жертвами насильственной стерилизации. Эти вмешательства имели место на всей территории Соединенных Штатов, существовали законы штатов, санкционирующие подобные действия по отношению к людям, признанным неприспособленными по мнению американских социальных инженеров. Впрочем, эта проводимая масштабно кампания по очищению популяции США вдохновила в конце концов Адольфа Гитлера. И не только. И хотя деятельность АВА уже давно осталась в прошлом, сама идея евгеники и ее практическое применение распространилось по миру как эпидемия. Несмотря на трагический опыт Второй мировой войны, евгеника функционировала в США до 80-х годов ХХ в., в Швеции до 70-х (там были насильственно стерилизованы тысячи людей), в Польше до 50-х (хотя здесь евгеника никогда не была санкционирована юридически $)^{19}$. Евгенические инциденты, связанные со стерилизацией умственно отсталых людей имели место в Канаде, Исландии, Австралии, Эстонии, Швейцарии, Норвегии и Финляндии. Это очень сложное явление, ему посвящено уже большое количество развернутых работ, на которые в этом месте уже нет смысла ссылаться. Существенной для рассуждения информацией является факт, что межгрупповые антагонизмы, возникшие в связи с социальной имущественной стратификацией, могли приобретать весьма радикальные и негуманитарные формы - такие как американская кампания, предполагавшая, во-первых, наследственность бедности, a, во-вторых, - необходимость постепенной физической элиминации бедных.

\section{3. Заключение}

Из всего вышесказанного можно сделать следующие выводы: сама частная собственность как институт, также как и общественное решение о ее принятии или отрицании,

18 E. Black, War against the Weak. Eugenics and America's Campaign to Create a Master Race, Вашингтон 2003, С. 204.

19 M. Bobako, Eugenics and breeding of race (доклад), 2013-04-24, UAM Познань. 
410 | Adam Mickiewicz University Law Review

непосредственно не провоцирует нежелательных явлений с социологической точки зрения. Появляются они в связи с интерпретацией и оценкой естественных следствий имущественного расслоения, которое возникает в коллективах, хозяйствующих с допущением этой собственности. Разделение на более богатых и более бедных, совмещенное с повсеместным признанием полной ответственности личности за свой материальный статус, может привести - и нередко приводит - к социальным проблемам. Особенно люди, занимающие крайние позиции в имущественной стратификации, подвержены различному в своем проявлении осуждению. Следовательно, даже если мы в состоянии оценить институт частной собственности в экономическом и личностном плане (каждый имеет право владеть и приумножать богатство), тем не менее, весьма часты проблемы с принятием последствий ограниченного количества ресурсов в экономике и дифференциации на более и менее состоятельные группы. Или вокруг этого вопроса создаются отдельные теории, ведущие к социальному конфликту, который нередко протекает весьма трагически, или же фактор актуального имущественного положения является дополнением стратегии обличения определенных лиц по этическим, религиозным или национальным соображениям. В любом случае это приводит к серьезным злоупотреблениям в человеческих взаимоотношениях.

\section{Биографическая аннотация:}

Aleksandra Łopińska - аспирантка в Институте Социологии, Университет им. Адама Мицкевича в Познани. Научные интересы: миграционные процессы, социальная и политическая трансформация бывших советских республик и экономическая история КНР.

SUMMARY

Financial state, position, class. Private property as a factor regulating modern social differences

The aim of the study is to evaluate the private property as a factor regulating modern social differences. Proving the proposed hypothesis the author focus on the financial state, position and class as a forms of social differences in the context of the civil law system.

KEYwords: private property, social differentiations, civil law 